Brocar, 18 (1994) 223-250

\title{
EL PÓSITO DE SANTO DOMINGO (1579-1699)
}

\section{J.G Torrealba}

RESUMEN: Los pósitos fueron, durante la Edad Moderna, una pieza clave de la política económica municipal, tanto para asegurar el abastecimiento de un producto básico, el pan, como para servir de instrumento a las oligarquías locales en sus intereses. Fue en el terreno del control de la economía donde mayor autonomía mantuvieron las villas y ciudades castellanas durante el "siglo del Absolutismo". En consonancia con esta autonomía, los pósitos demostraron una gran capacidad de adecuación a las circustancias de cada municipio, en función de diversos factores tales como la importancia de la producción de trigo, el grado de especialización y comercialización, el tamaño de la pobalción o el grado de oligarquización, entre otros. En el caso de Santo Domingo de la Calzada puede observarse como un modelo de gestión poco adecuado se transformó en el paso del siglo XVI al XVII y en el contexto de la crisis provocada por la peste de 1599, para convertirse en un instrumento de gran eficacia en la segunda mitad del Seiscientos.

ABSTRACT: "Pósitos" were, during Modern Age, a key piece in municipal economic policy, not only in order to warrant customers food-supply of a basic product, bread, but to serve as an instrument for local elites in their own interest. It was in economic control where the castillian villages and towns kept more autonomy in the "Century of Absolutism". According to such autonomy, public granaries showed a great capacity to fit the diferent caracterists of each population, depending of several factors such as the importance of wheat production, the degree of specialization, the size of population or the concentration of power in a few hands, among others. In Santo Domingo de la Calzada can be seen how a management model not well adapted change in the last years of 16th Century, in the context of crisis produced by pest of 1599, to become a efficient tool in the second half of 17th Century.

Durante los siglos XVI y XVII se desarrolló el proceso de formación del Estado Absoluto por el cual, entre otros fenómenos, las ciudades y villas castellanas fueron 
perdiendo parcelas de poder en beneficio de la Corona, que fomentó la constitución de ayuntamientos cerrados, en los que la mayoría de los vecinos dejaron de tener apenas ningún papel activo. Durante el Seiscientos se consolidó la oligarquización de los municipios y la patrimonialización de los oficios públicos por unas pocas familias ${ }^{1}$. Aunque con ello se estimuló la corrupción y se aumentó el poder de unos pocos, estos grupos eran más susceptibles de doblegarse a las presiones del poder de la corona, lo cual, en definitiva, significaba un aumento real de su capacidad de intervención. No obstante la intromisión de un Estado cada vez más presente no avanzó en todos los terrenos por igual ${ }^{2}$. Por una parte, la pertenencia de un municipio a un territorio de señorío suponía un factor que complicaba las relaciones con el gobierno de la monarquía, representando el señor una instancia mediadora de muy diversa importancia según el caso ${ }^{3}$. Dentro de las areas de realengo, las necesidades apremiantes de dinero para mantener una política internacional desproporcionada con sus recursos limitaron los escrúpulos que pudieran suscitarse acerca de cómo se recababan los fondos en cada pueblo castellano, siempre que se cumplieran religiosamente los pagos. En este contexto se insertan el ingente aumento de la presión fiscal y la propia venalidad de cargos a partir, sobre todo, del reinado de Felipe II.

En el terreno de la intervención económica fue, probablemente donde más lentamente se desarrolló la capacidad de control del rey y donde más independencia conservaron los gobiernos municipales al servicio de unos intereses patrimoniales locales muy concretos ${ }^{4}$. Es innegable que el peso de la presión fiscal constituyó por sí mismo un elemento en muchos casos determinante de la política económica adoptada por los municipios. Además no se limitó a la imposición de contribuciones más o menos onerosas. El estímulo que se dio durante todo el siglo XVII al entablamiento de pleitos largos y costosos y a la compra de honores muchas veces inútiles, representó una fuente de ingresos no desdeñable para la monarquía y, sobre todo, una sangría interminable para los recursos de las haciendas locales y de muchos patrimonios personales. Las sucesivas perpetuaciones y "consumos" de oficios, la compra de jurisdicciones o la consecución de exenciones de jurisdicción, la adquisición de títulos de ciudad o de villazgo, implicaban, además de enormes costas legales, "servir" al rey con cantidades fabulosas para las posibilidades reales de muchos municipios. Pero así como en el terreno político y social se establecieron unas pautas de intervención en el ámbito municipal más o menos coherentes con los intereses de la

1. Un ejemplo modélico y muy próximo geográfica y temporalmente de este proceso puede verse en LORENZO CADARSO, 1995, pp. 261-271 y, en general, en todo el capítulo VI.

2. Para el caso de La Rioja, vid. Gómez Urdáñez y Lorenzo Cadarso, 1993, pp. 79-92.

3. Sobre el señorío en La Rioja vid. Gómez Urdáñez y Armas Lerena, (en prensa).

4. Para el caso de Logroño estos aspectos pueden seguirse en Burgos Esteban, 1989, pp. 91-117; y en Armas Lerena, 1989.

5. Gran cantidad de poblaciones riojanas sufren concurso de acreedores a sus propios. Sobre la administración de las rentas de propios de Logroño Cfr. Armas Lerena, 1989. Otro caso emblemático es Alfaro, población cuyas rentas (incluyendo el Pósito) se esfuman para adquirir el título de ciudad, a mediados del siglo XVII. 
monarquía, en lo económico resulta mucho más complicado encontrarlas antes del siglo XVIII. Ciertamente el proceso de elaboración de las Ordenanzas municipales, uno de los elementos fundamentales en la conformación de la política económica local, estaba sujeto a la aprobación del Consejo de Castilla o de la Chancillería de Valladolid, después de su aprobación en Concejo abierto. Pero la atención de estos órganos centrales se fijaba fundamentalmente en las ordenanzas de gobierno, de contenido principalmente político y guardaba estrecha relación con la importancia de la población de la que se tratara. Además, ese control indirecto ejercido sobre cada localidad en concreto se correspondía con el fraccionamiento característico del Antiguo Régimen en todos los ámbitos — político, social y económico- y difícilmente podía contribuir a superarlo para convertir una suma de entidades heterogéneas en una estructura territorial realmente integrada.

Por otro lado, la aplicación cotidiana de los reglamentos se llevaba a cabo por grupos sociales que los usaban para defender corporativamente sus intereses económicos. El único obstáculo que tenían que afrontar, además del cumplimiento de las obligaciones fiscales con la Hacienda Real, era el delegado de la autoridad regia. El corregidor, oficio que quedó totalmente al margen de la venalidad de cargos, que nunca perdió su carácter temporal y que sufría exámenes periódicos en general bastante rigurosos, los Juicios de Residencia, además de otros extraordinarios, era un elemento fundamental para el organigrama de poder del absolutismo en los territorios de realengo castellanos. Pero si sus atribuciones puramente políticas estaban más o menos bien determinadas y su autoridad en ese terreno tenía un peso relevante, no sucedía lo mismo en la dirección de los asuntos económicos y especialmente en la organización del abastecimiento de la localidad en la que radicaba. En una fecha tan tardía como 1742, en el manual de Santayana Bustillo se dice:

«Pertenece, pues, el gobierno político y económico de los pueblos a los Ayuntamientos o Concejos de ellos, y tan privativamente que, no habiendo queja de parte o instancia fiscal, no pueden las cancillerías o Audiencias entrometerse en estos asuntos» ${ }^{6}$.

Poco después añade:

«El hacer Ordenanzas es privativo y peculiar de los Ayuntamientos o Concejos. No es necesario se junte el pueblo para establecerlas. En su formación sólo los regidores tienen voto; no el corregidor, que, como ya se dijo, sólo lo tiene decisivo en concurrencia de votos iguales, si bien será de su inspección ver si el pueblo necesita o no de que se hagan Ordenanzas para su régimen ${ }^{7}$

6. SANTAYANA BUSTILLO, 1979, p. 7. Esta obra es una versión actualizada de la Política para Corregidores y señores de Vasallos, de Jerónimo Castillo de Bobadilla, que tuvo tanta trascendencia desde su publicación hasta comienzos del siglo XVIII.

7. SANTAYANA BUSTILLO, 1979, p. 38. Estas afirmaciones aparecen matizadas a lo largo del capítulo IV de la obra, pero no hay lugar aquí para entrar en ello. El valor del texto es aproximativo a esta cuestión y no debe entenderse llevado a sus últimas consecuencias. 
En realidad, para mediados del siglo XVIII y, sobre todo, a partir de los capítulos para corregidores de Fernando VI, el papel de los representantes reales se había reforzado considerablemente, también en cuestiones económicas ${ }^{8}$. Hasta cierto punto, existe un desfase entre la obra citada y a situación real, los primeros síntomas de cuyo cambio se habían dado ya en la última etapa del reinado de Carlos II. Pero, en cualquier caso, las atribuciones privativas de los regidores en materia de control económico y especialmente de la organización del abastecimiento fueron durante el siglo XVII y en la mayoría de las poblaciones castellanas, muy extensas.

Dentro de ese terreno, el producto más perentorio, cuya necesidad era más básica desde todos los puntos de vista, era el pan. Para lograr un buen aprovisionamiento no podía confiarse sólo en la libre concurrencia al mercado, tanto por razones de producción como de la dinámica del propio mercado. Por un lado, las limitaciones técnicas atenazaban la producción y comercialización de este como de otros artícu$\operatorname{los}^{9}$. Las dificultades físicas, pero también jurídicas y sociales que encontraba el comercio de granos condicionaban todo el sistema económico. Al no poder contar fácilmente con el suministro habitual de zonas alejadas, cada comarca se veía obligada a producir como mínimo una cantidad suficiente para cubrir un alto porcentaje de sus propias necesidades. Con ello se fomentaban unas altas tasas de autoconsumo entendiendo aquí como unidad de producción la comarca, no el campesino- y unas posibilidades muy escasas de especialización regional. Existía un fuerte fraccionamiento en pequeños mercados con sus propias coyunturas de escasez y abundancia. La banda de oscilación de los precios tanto interanuales como estacionales era por ello muy amplia. En este contexto la dinámica de los mercados contribuía a agravar el problema, al incentivar el acaparamiento y la especulación.

Para enfrentarse a estos problemas y amparándose en el armazón ideológico de las teorías de justiprecio orientadas a la protección del consumidor, los Pósitos se erigieron en muchas poblaciones como instrumentos de control sobre un comercio vital. Su importancia fue puesta de manifiesto hace ya bastante tiempo por Gonzalo Anes en su artículo clásico ${ }^{10}$. Según este autor, su función era triple: por un lado cuidaba del aprovisionamiento de los núcleos en los que estaba instalado, amortiguando los efectos de las malas cosechas en los consumidores tanto en cuanto a cantidad como en cuanto a precios. En cierto sentido tendería así a limitar la especulación de los grandes acaparadores en los años más difíciles. Por otro lado, constituía un auténtico instituto de crédito rural a nivel municipal, prestando a los campesinos dinero o grano para la sementera en años de escasez, cobrando un bajo interés (algo más del cuatro por ciento por lo general) para cubrir los gastos de organización y el riesgo

8. No obstante este proceso se desarrolla de forma un tanto irregular en función de la capacidad de resistencia y de presión de las oligarquías locales implicadas. Cfr. ARMAS LERENA 1994, en el que se trata del conflicto que enfrentó al corregidor D. José Manuel Trelles con los regidores logroñeses. vol. II.

9. Sobre las condiciones de la producción en La Rioja Vid. Ibáñez Rodríguez, 1991, y Brumont, 1986,

10. ANES, 1972. 
que suponía el préstamo. Algunos pósitos, por último, lograban un superávit que les permitía realizar obras de interés público (mejora o construcción de puentes, caminos, etc). A pesar de estas variadas actividades, la fundamental para Gonzalo Anes es la segunda, la relativa a los préstamos.

De esta caracterización se desprende -al igual que de cualquier fuente oficial que podamos consultar sobre los pósitos- una imagen idílica en la que unos representantes del poder político abstractos -en cuanto que no representan intereses particularesgestionan de forma más o menos altruista una institución que viene a amortiguar unas deficiencias estructurales, al menos cuando estas se hacían patentes de forma dramática en coyunturas concretas de escasez. Pero las personas que dirigían estas instituciones no eran funcionarios asalariados sino que habían pagado un alto precio por la posesión de sus oficios para usarlos en su propio beneficio. Además del criterio de eficacia en su función de colchones para reducir el impacto de las carestías sobre los consumidores, en la gestión de los pósitos intervenían también otros móviles. En manos de las oligarquías locales se convirtieron en eficaces instrumentos a su servicio, dentro del organigrama del abastecimiento en general y del reglamentismo económico municipal. Este hecho, unido a las amplias atribuciones de que gozaban los regidores condujeron a un proceso de adecuación de los graneros públicos en el tiempo y en el espacio a circustancias diferentes. Existen por este motivo variaciones en los modelos de gestión de los pósitos de diversas localidades y, dentro de ellas, entre unas épocas y otras, en función de diversos factores. La mayor o menor importancia de la producción de trigo en la comarca afecta de diversas formas a las necesidades de la población. Existe una gran diferencia entre las necesidades más perentorias pero también ocasionales de una comarca excedentaria en años de cosechas normales, por un lado, y las necesidades permanentes y más regulares de otra deficitari $\mathbf{a}^{11}$. La mayor o menor concentración de la propiedad y el grado de especialización y comercialización puede implicar una estructura más o menos oligárquica del poder municipal vinculada a unos intereses económicos diferentes. Otros aspectos determinantes son el tamaño de la población, su adscripción al realengo o el régimen señorial que soportan, y la capacidad de presión de las oligarquías locales en instancias de poder superiores. Todos estos elementos se interrelacionan de una manera muy compleja, dando lugar a una variedad de estrategias respecto a la cuestión que aquí nos interesa, a veces solamente de matiz, en otras ocasiones de fondo.

El caso que se muestra en el presente artículo, centrado en el Pósito de Santo Domingo de la Calzada, presenta como peculiaridad el hecho de que nos ha sido posible recoger información de dos modelos de gestión muy diferentes separados por 75 años y que, además, se ha podido analizar el momento en el que se produce el paso de uno a otro, en la terrible crisis que asoló Castilla en el tránsito del siglo XVI al XVII.

11. Ejemplos de modelos dispares de estructuras económicas pueden verse en GÓMEZ URDÁÑEZ, J. L. y otros, 1987; del mismo (como director del area de $\mathrm{H}^{\mathrm{a}}$ Moderna), 1995, tomo III; PASTOR OCÓN, 1989; Alonso Castroviejo, (en prensa). 
Por su altitud, por encima de los $600 \mathrm{~m}$., Santo Domingo de la Calzada se encuentra fuera de la zona donde la producción vinícola tiene mayor protagonismo, ocupando el cultivo de cereal el primer puesto de la actividad económica ${ }^{12}$. A comienzos del siglo XVIII hubo un intento de impulsar el cultivo de la vid. La relación entre los precios del pan y del vino era muy favorable a este desde mediados del siglo XVII y lo seguiría siendo durante buena parte del XVIII. Los argumentos del municipio cuando pide al Consejo de Castilla la aprobación de las ordenanzas dejan entrever,

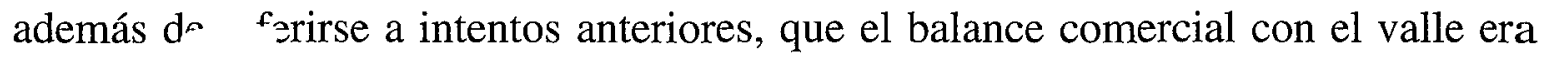
muy negiuvos para su ciudad:

«Reconoziendo esta ciudad lo mucho que de algunos años a esta parte se an estenuado los caudales de sus vezinos y examinando con particular cuidado [...] los motivos de haverse ido apurando tanto los comercios y granjerias [...] estendiendo la vista al principio y orijen que tubo esta decadencia parece ser que todo su daño, o la maior parte de el, proviene desde el tiempo que faltan las viñas, pues desde entonces son muchas las cantidades de dinero que salen de esta ciudad para la compra y porte de vinos que nezesita, con gran detrimento de los jornaleros que, por faltarles el util de el cultivo, unos se an dado a la ociosidad y otros se an aplicado a los montes con poco adelantamiento de su trabajo por la cortedad que les rinde la leña; otros se an reducido a ir por temporadas a cavar a la Rioja dejando sus familias con solos los socorros de la providencia; y otros que an seguido el trabajo y granjeria de sus labranzas, no pudiendo avarcar con las tierras de sus muchos arriendos y de sus pocas fuerzas, se an perdido por la codicia de arrendar por algo mas a los lugares circunvezinos las tierras mejores reservando para si las ruines con el motivo hunico de estar mas contiguas a esta ciudad; y deseando proveer de remedio si no a tantos males al menos al que se juzga por origen de ellos resolvio y determino esta ciudad se bolviese a el cultivo y comercio de viñas ... ${ }^{13}$.

Ese intento fracasó. Precisamente el texto citado se recoge como antecedente en una nueva petición realizada cuarenta años más tarde en la que se repiten prácticamente los mismos argumentos ${ }^{14}$, aunque destinando otros términos del municipio en los que se asegura que podrá prosperar la producción de vino. En cualquier caso

12. Según las investigaciones en curso de S. Ibáñez Rodríguez, la producción de centeno fue mayor que la de trigo durante los siglos XVI y XVII, para abastecer a las caballerías que unían comercialmente el valle con la sierra. En cualquier caso parece claro que la comarca era generalmente excedentaria de trigo, lo cual es más relevante a la hora de analizar el funcionamiento de su pósito.

13. A.H.N., Consejos, leg. 31.854. Introducción al texto de las ordenanzas cuya aprobación se solicita al Consejo de Castilla. La copia termina de forma abrupta, sin inclusión de fecha exacta, aunque en ella se menciona el año 1704 para el inicio de su aplicación.

14. El texto que encabeza la copia de las antiguas ordenanzas, desenterradas a mediados de la década de 1730 para su nueva aplicación, es un alegato del Procurador Síndico General en el que refiere cómo en 1704 se aprobaron ciertas ordenanzas para la conservación de la República y plantío de viñas. Entre ellas, una permitía plantar viña en los términos de Pino y las Llanas. Con el tiempo se vio que dichos términos eran poco apropiados para ello, por lo que se fueron replantando de trigo y descepando, lo cual había perjudicado mucho a la villa. "Y haviendo reconozido que a los términos de los Herios, la Nona y Arratras que sirben desde que se hizo el deszepo antiguo para fructificar mieses las más deviles y delicadas como son zevadas, abenas, zentenos y comuñas, es a propósito para el plantío de viñas..." se solicitaba la aprobación de unas nuevas ordenanzas. 
queda claro que durante el periodo que abarca este estudio, la presencia de la viña tuvo un carácter puramente anecdótico.

Al contrario que en otras poblaciones de la Rioja Baja, donde existía una producción vinícola de cierta importancia y abundaban los sotos inundables, muy propicios para el cultivo del cáñamo y del lino, en Santo Domingo el grado de especialización en la producción de trigo era mucho más marcado. No sólo se autoabastecía, sino que el comercio de granos hacia la comarca de Haro, donde primaba fundamentalmente el cultivo de la vid, tenía una gran importancia. El mercado calceatense tenía suficiente notoriedad como para atraer agricultores de una comarca bastante amplia y centralizar en buena medida el comercio de cereal desde el tramo de sierra que comprende las cabeceras y cursos medios de los ríos Tirón, Oja y Tuerto, llegando su influencia a abarcar una parte de la comarca de Miranda de Ebro ${ }^{15}$.

La preeminencia del cultivo de trigo estaba acentuada por la ausencia de otro comercio de importancia, al no contar Santo Domingo con una aduana. A pesar de formar parte del camino de Santiago, cuya importancia como vía comercial había decaído hacía mucho tiempo, no se puede considerar como una etapa destacada salvo en lo que se refiere a la peregrinación religiosa. Siendo cosede del obispado, junto con Logroño y Calahorra, el Obispo no residió prácticamente nunca allí, y sus cabildos eclesiásticos no tuvieron una importancia tan radical en la vida de la localidad como en Calahorra o Logroño ${ }^{16}$.

Jurisdiccionalmente, era una villa de realengo, sede de un corregimiento de escasa importancia. Por su dimensión demográfica y económica y al no estar en ninguna frontera, constituía una jurisdicción de segundo orden, sobre todo en comparación con los corregimientos de Logroño y Agreda. Cuando, a causa de la peste de 1599 el corregidor huye de la ciudad y el cabildo nombra a un teniente de corregidor para atender las funciones judiciales, la Corona no se da ninguna prisa en sustituirlo. Tratándose de una crisis general en toda Castilla, es comprensible que hubiera otras prioridades, pero el lamento del cabildo municipal no deja de resultar sangrante:

«Don Alonso Mendez de Parada, corregidor desta ciudad, ha más de diez meses que hiço ausensia della y nunca a buelto; dejó la bara en su ausensia al liçençiado Francisco de Oçio, abogado y veçino desta çiudad el qual ha hecho el oficio todos los diez meses asta que fue requerido con quarta carta de V(uestra) Mag(esta)d sobre tres que se abian notificado al dicho Don Alonso para que no lo hiçiese, el qual obedecio y cumplio luego la quarta carta; y porque la ciudad no quedase sin just(ici)a se junto al punto el ayuntamiento y nombraron por alcaldes que administrasen justicia, en el ynterin que a V. Magd se daba noticia, a Xristobal de Ubago y Florian de Arana, regidores de la dicha ciudad; Esta çiudad suplica a V. Magd con todo encarecimiento se sirba prober corregidor que benga al punto, por que se padeçe mucho en esta ciudad a causa de la enfermedad, que se ba dilatando... $\gg^{17}$.

15. Vid. más adelante, comentario de las cuentas de 1579-82.

16. Cfr., Ibáñez Rodríguez, 1995.

17. A.H.N., Consejos, leg. 27.900. 
Posteriormente hay una denuncia del corregidor, alegando haber nombrado teniente de fuera de la ciudad y acusando a Francisco de Ocio y a un sector del Ayuntamiento de usurpadores. Una acusación poco verosímil, atendiendo al estado de la ciudad que se describe a continuación del texto citado ${ }^{18}$.

A pesar de su falta de importancia o, quizás, precisamente por ello, las arcas municipales sufrieron mucha menor presión fiscal por parte de la Corona. Al menos sus finanzas estuvieron muy saneadas durante toda la segunda mitad del siglo XVII, momento en el que los propios de numerosas poblaciones se hallaban sometidos a concursos de acreedores. En cuanto a las coyunturas políticas, a juzgar por los oficiales municipales que figuran en los encabezamientos de las sesiones del Ayuntamiento, parece existir bastante estabilidad. A finales del siglo XVI, los regidores son ya perpetuos y los apellidos de los titulares se repiten en una proporción bastante alta hasta finales del XVII. Parece que el proceso de oligarquización del municipio se consolida tempranamente. Al menos no hay rastros de las luchas intestinas que dividieron a las élites de otras poblaciones en función de diferentes intereses económicos (cosecheros frente a ganaderos en Haro desde la segunda mitad del siglo XVII; mercaderes frente a cosecheros en Logroño durante la primera mitad del mismo siglo); luchas intestinas que arruinaron en muchos casos las arcas municipales que en Santo Domingo, como decíamos, tuvieron gran solidez durante toda la centuria.

Para analizar el aspecto concreto de la política municipal que aquí se trata, se disponía, en principio, de una documentación dispersa en cuanto a los limites temporales, proveniente toda ella de los juicios de residencia. Corresponden estos controles administrativos a los siguientes trienios: 1579/82, 1642/45, 1684/86 y 1969/99'. Esta lasitud presenta un grave inconveniente respecto a la continuidad y a la posibilidad de establecer series mínimamente amplias de precios, cantidades, etc. No obstante, la casi exacta similitud de las cuentas del siglo XVII ofrecen una imagen muy coherente del funcionamiento del pósito durante la segunda mitad de la centuria. En cuanto a la documentación correspondiente a finales del siglo XVI, ciertamente se aleja un tanto de los límites adoptados en principio para el estudio. Sin embargo, resulta extremadamente interesante debido a la radical diferencia que presentan esas cuentas respecto a las del siguiente siglo. Hasta tal punto es así, que se puede hablar de dos modelos de intervención e incluso de contabilidad totalmente distintos; uno más

18. El texto dice así: «...que se ba dilatando y como el obispo se salio con su audiencia y otras jentes se ban saliendo cada dia, la sisa biene a ser de muy poco provecho y ansi los pobres padecen extrema necesidad, que no ay de que darles de comer en los hospitales fuera desta ciudad donde estan; Esta çiudad tiene en pie dos mill ducados que abia tomado a çenso para el probeimiento de las carneçerias del año pasado; V. Magd se sirba que dellos se pueda dar de comer a los pobres y aun a los veçinos, porque como ha çesado el comerzio no venden cosa de sus oficios porque no entra persona en esta ciudad ha mas de dos meses porque de otra manera va perdida de todo punto esta ciudad». La data es de 31 de agosto de 1599.

19. A.H.N., Consejos, legs.: 25.420 para $1579 / 82 ; 28.034$ para $1462 / 45 ; 32.902$ para $1684 / 86$; y 26.534 para 1696/99. 
parecido al que puede observarse en Agreda o Logroño y el otro más próximo al de Calahorra.

A la documentación localizada en el A.H.N. se suma un Archivo Municipal de una riqueza extraordinaria. El periodo elegido para complementar los periodos mencionados arriba es el correspondiente a los años 1596 a 1603, en los que se desarrolla la gravísima crisis que sacudió Castilla a finales de esa centuria y que contribuyen a explicar el paso de una a otra de las formas de gestión a las que antes nos refería$\operatorname{mos}^{20}$.

\section{El Modelo de Gestión hacia 1580}

La contabilidad en la primera época es más simple que en otros casos. El periodo de administración iba, nominalmente, de Pascua de Espíritu Santo de un año a la del siguiente. La celebración de la fiesta de Pentecostés varía, en función de la Semana Santa, entre el 10 de mayo y el 13 de junio. Son los meses en los que se comenzaba habitualmente la venta del pan del pósito y, cuando posteriormente se desarrolle esa práctica, el "señalamiento" del trigo de la siguiente cosecha. A pesar de que el nombramiento del nuevo mayordomo se produjera en esa fecha variable, no debía hacerse efectivo hasta que concluía la venta del trigo por parte del administrador saliente. En aquellos años en los que ha sido posible reconstruir las fechas de las operaciones queda muy claro que la tarea de cada administrador se prolonga mucho después de que haya sido elegido su sucesor. No se entiende, en caso contrario, que lo que queda como capital inicial de la mayor parte de los ejercicios esté constituido casi exclusivamente por dinero líquido.

Se aplica, por supuesto, la contabilidad por partida doble. Pero mientras que para el trigo, el debe y el haber aparecen claramente separados, no sucede lo mismo para el dinero en metálico. El cargo en dinero está simplificado al máximo, y está compuesto, casi únicamente por dos partidas: el capital que el mayordomo entrante recibe del saliente y el producto de la venta del pan. Esta simplicidad se debe a que todas las operaciones contables se cierran dentro de cada campaña, evitando el traspaso de deudas en metálico a favor del pósito de un ejercicio a otro, gracias, en parte, a que es después de terminar las ventas cuando se realiza el relevo del administrador. Unicamente en el último año del trienio, ese primer apartado se complica debido al recurso al crédito, con motivo de una grave carestía.

Por lo demás, el orden establecido sigue unas pautas fijas bastante racionales. Tras la anotación del patrimonio inicial que recibe el mayordomo, se recogen las compras en las que se emplea, compras que se detallan con gran minuciosidad y que

20. Las cuentas que se conservan en el A.M.S.D. para el mencionado periodo son las siguientes: 1596/97, $1598 / 99,1599 / 1600$ y 1602/03. Todas ellas aparecen en el leg. 51 (según una catalogación provisional que no llegó a completarse, elaborada por el grupo Petra) en el que se conservan las cuentas de más de cincuenta años no consecutivos de los siglos XVI al XVIII. 
constituyen el cargo de trigo. A continuación se registran las ventas, en las cuales se emplea todo el cereal adquirido, de manera que no queda ningún remanente para el año siguiente. El producto de esta operación constituye la segunda partida del debe, que se suma al patrimonio inicial. Por último, se detraen de esta cantidad los gastos ocasionados por las compras y la gestión, quedando como resultado el capital disponible para la siguiente campaña.

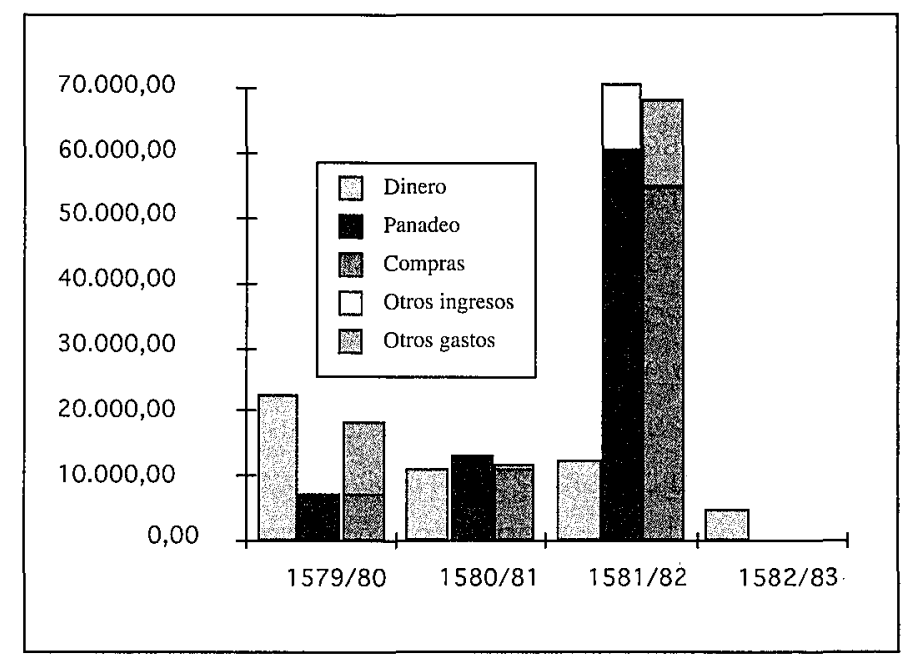

Gráfico 1: Evolución del patrimonio, los ingresos y los gastos.

El patrimonio inicial del pósito es relativamente estable en la corta muestra recogida (ver gráfica 1) rondando un poco por encima de los 10.000 reales. La razón de que en la primera administración aparezcan algo más de 22.000 es que en algún momento anterior se ha contraído un censo de 1.000 ducados que precisamente se redime en ese año. En la última campaña, las pérdidas experimentadas a causa de la carestía son cuantiosas, a pesar de que el Corregidor obliga a un grupo de regidores a contraer censos por valor de algo más de 10.000 reales. Como consecuencia, el año siguiente el mayordomo recibe una cantidad muy pequeña de dinero, menos de la mitad de otros años.

La cifra puede resultar pequeña en términos absolutos comparada con las de otras poblaciones riojanas. Pero hay que recordar que estas cuentas corresponden a finales del siglo XVI. A pesar de que teóricamente la década de 1580 es aproximadamente el momento en el que la inflación de la centuria llega al máximo, los precios de compra de trigo en los años normales son bastante más bajos. Por otro lado, la población de Santo Domingo es menos numerosa. Hay que pensar, pues, que en términos relativos el dinero disponible constituye una cantidad considerable para los años de cosechas ordinarias.

El primer año lo invertido en compras de trigo supone solamente alrededor del $60 \%$ del capital inicial. El segundo año se emplea la totalidad del dinero, adquiriéndose casi el doble de trigo a un precio algo inferior al del anterior. Se aprovecha la coyuntura favorable para incrementar en algo más de 1.000 rs. (un 8\%) el patrimonio de la institución. En la campaña de 1581/82, la elevación brutal de los precios convierte los recursos en totalmente insuficientes. Los 12.500 reales disponibles 
suponen sólo un $23 \%$ de lo que cuestan las más de 3.000 fanegas adquiridas, eso sin contar con otros gastos extraordinarios motivados por la crisis. Incluso sumando los censos forzados a que antes nos referíamos, el porcentaje no alcanza, ni con mucho el 50\%. Queda claro que dos años consecutivos de cosechas excepcionalmente malas podían llevar a la bancarrota, incluso con las medidas adoptadas que ense guida comentaremos. La insuficiencia de los recursos disponibles para afrontar las crisis más graves quedaría patente cuando, dieciséis años más tarde, en 1598, se solicitara a la Corte licencia para contraer un censo por valor de 2.000 ducados -el doble del patrimonio habitual veinte años antes - para comprar trigo para el pósito por no haber habido cosecha ${ }^{21}$; petición hecha a pesar de que entre 1583 y 1596 el capital de la alhóndiga había pasado de 4.000 reales en la primera fecha a más de 38.000 en la segunda.

Siguiendo el mismo orden contable que fija la fuente, pasaremos ahora a comentar los lugares de los que proviene el trigo ${ }^{22}$. En primer lugar hay que señalar que casi con total seguridad estas operaciones se desarrollaban en el propio mercado de la ciudad. No hay indicación de portes ni de dietas del mayordomo u otra persona que justifiquen desplazamientos por este motivo. Además, las partidas señaladas suelen ser demasiado pequeñas como para justificar tales desplazamientos. Unicamente en un caso cabe pensar que sí hubo una importación organizada por el granero público. En efecto, en el primer ejercicio del trienio, entre los lugares de procedencia del cereal, figura Logroño en el tercer puesto, con un 16,38\% del trigo comprado cuya cuantía fue ciertamente escasa. Sabiendo que se trata de un núcleo de población altamente deficitario de granos por su especialización vitivinícola, cabe suponer que ningún agricultor logroñés se desplazaría $46 \mathrm{~km}$. para vender 40 fanegas (la partida más cuantiosa) en un mercado tan alejado. Las personas que venden estas partidas son canónigos $^{23}$, así que resulta muy verosímil que se aprovecharan las relaciones personales entre eclesiásticos de las dos poblaciones como contactos comerciales para contratar las compras.

Fuera de este caso puntual y de lo que sucede a causa de la carestía en el último ejercicio, que trataremos aparte, todas las demás se refieren a localidades muy próximas, alejadas como máximo unos $20 \mathrm{~km}$. Entre ellos destacan Treviana, Valluércanes, Tormantos, Cerezo (suman el 58\% del trigo adquirido en 1579), Leiva y Redecilla (estas dos últimas junto con Cerezo y Tormantos son el origen del $42,27 \%$ del comprado en 1580). La diferencia más notable que se aprecia entre los datos de las dos primeras campañas es que, mientras en la primera el trigo de los vecinos de Santo Domingo que pasa al pósito es muy poco (apenas un 3,5\%), en la segunda representa más del $28 \%$, con un precio, por cierto, medio real más bajo que

21. A.M.S.D., Cuentas del Pósito, leg. 51. La fecha de la concesión de dicha licencia es el 27 de noviembre de 1598. Como luego se verá, este censo nunca llegó a emplearse en la compra de trigo, sino en la de carne.

22. Ver mapa 1

23. El licenciado Anguiano vende 32 fanegas el 5 de septiembre de 1579 y otras 40 el 10 del mismo mes. Ese mismo día se compran otras 32 fanegas al canónigo Osorio. 
la media en ambas ocasiones. Todas las compras, se producían de forma poco escalonada, justo después de la cosecha, cuando los precios eran los más bajos del año. La mitad del cereal se adquiría en octubre y el resto entre septiembre y noviembre.

La zona de abastecimiento, limitada al vecino valle del Tirón, cambió considerablemente como consecuencia de una carestía severa. En 1581 la cosecha fue muy mala. El precio del cereal de los lugares próximos comenzó a subir rápidamente y antes de terminar septiembre había superado los 15 reales por fanega y llegaría a 20 en noviembre. En primavera se procedió al embargo del trigo de los vecinos al precio de la tasa, a 14 reales. Se consiguieron solo algo más de 800 fanegas. Sin duda esto hubo de influir en el hecho de que los vendedores que acudían a Santo Domingo habitualmente se retrajeran o se encaminaran a Miranda de Ebro. Allí tuvieron que dirigirse los munícipes para sus compras, encontrando precios de hasta 26 rs. Entre los vendedores figuraban vecinos de poblaciones muy próximas como Cerezo, e incluso de la propia ciudad. El aumento de precio hizo rentable traer trigo desde Burgos, a $70 \mathrm{~km}$. de distancia, y de Frómista y Boadilla del Camino, a unos 140. Incluso con los portes - que representaban un tercio del coste final en el caso de las localidades palentinas - resultaba más barato que el de Miranda.

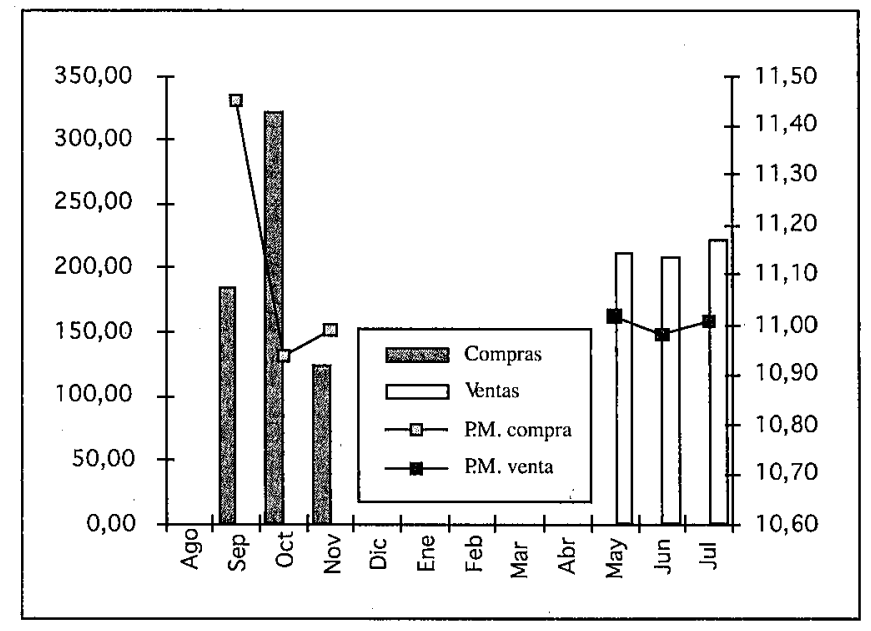

Gráfico 2: Compras y ventas del pósito de Sto. Domingo en 1579/80.

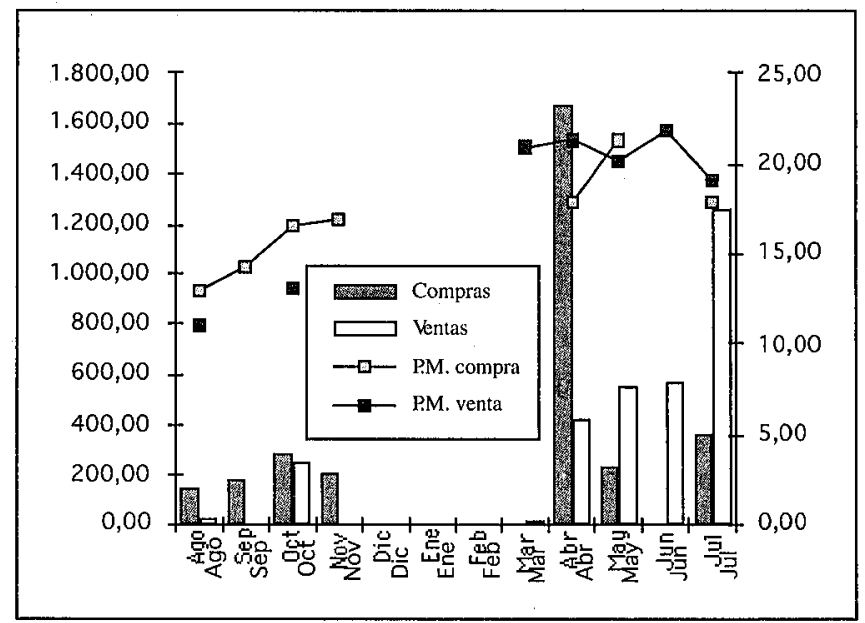

Gráfico 3: Compras y ventas del pósito de Sto. Domingo en 1581/82. 
La crisis alteró no sólo los lugares sino también la distribución de las compras y las ventas a lo largo del año respecto a un periodo con cosecha normal (véase gráfi$\cos 2$ y 3 ). Las mayores cantidades se adquirieron en abril, mes que concentra el 54\% del total de aquella administración. De este, la mitad aproximadamente corresponde al embargo hecho en Santo Domingo y la otra mitad a las compras de Miranda. El mayor escalonamiento concuerda con la necesidad de reunir recursos para seguir comprando ya que, como veíamos antes, el capital inicial no alcanzaba una cuarta parte del dinero que hubo de emplearse.

Entre 1579 y 1582, la única función del pósito es la venta de trigo. En su desarrollo se puede constatar una peculiaridad. En otros casos lo habitual es que el pósito venda el pan a los vecinos por mediación de algunas de las panaderías que reciben, a cambio de su trabajo, una parte del precio o una cantidad de pan - como en el caso de Logroño-, de tal forma que el producto y el dinero son en todo momento propiedad de la institución. Es ella la que debe asumir las pérdidas si los precios bajan y la venta se realiza con problemas, o guardar el pan ya elaborado. En Santo Domingo, el pósito vende trigo en pequeñas partidas a las panaderas, entre otros clientes, desentendiéndose después de él. Entre ellos aparecen vecinos de la propia ciudad, pero también de otras poblaciones próximas como Rodezno, Santurdejo o Corporales; es decir, precisamente de algunos de los lugares de los que proviene lo que se ha adquirido en el mercado de la ciudad, como veremos en seguida. Incluso, en un caso, se venden 20 fanegas a las panaderías de Grañón. De tal manera que las posibilidades de adecuación a distintas coyunturas se basan, entre otros recursos, en la ampliación o reducción del área geográfica de intervención.

Al llegar la carestía por supuesto se suprimieron las ventas a forasteros. En un principio aún se prosiguió vendiendo directamente el trigo en el mercado, o a las panaderías. Pero tras procederse al embargo, el Ayuntamiento ordenó que el pósito se encargara directamente de la venta del pan. A tal fin mandó construir un edificio específico, cuyo coste fue de algo más de 750 reales, lo cual no hizo sino agravar las pérdidas sufridas.

Resumiendo, las medidas extraordinarias adoptadas más destacables fueron cinco: la contratación de censos a nombre de los regidores, forzada por el corregidor; la interrupción de las ventas al exterior; la expropiación compensada al precio de la tasa; la aplicación de un control directo sobre la venta del pan; y el recurso a zonas más alejadas de compra. Estas medidas resultaron insuficientes para capear el temporal. El precio al que los vecinos de Santo Domingo pudieron adquirir el alimento básico fue más del doble del de los dos años anteriores. El pósito, por otro lado, perdió buena parte de su capital.

\section{EL CAMBIO DE GESTIÓN: LA CRISIS DE 1599}

En el último quinquenio del siglo se produjeron una serie de novedades que perfilan el nuevo modelo de gestión vigente durante el siglo XVII. En el primero de los ejercicios que recoge la muestra, las fórmulas de intervención y contabilidad son muy parecidas a las de quince años antes. Pero aparecen ya algunas modificaciones. La primera se refiere al volumen de negocios. Habíamos dejado la alhóndiga en 1583 
con sólo unos 4.000 rs. de capital. Al iniciarse el ejercicio de 1596-97, a pesar de los problemas comentados, contaba con más de 38.000 rs. No sabemos cómo se consiguió un aumento de recursos tan espectacular, aunque sin duda no fue ajeno a ello e1 recurso al crédito. Por otro lado, también se multiplica el volumen de trigo manejado. Las 3.096 fanegas compradas en 1582 en situación de carestía severa, pasan a constituir una cifra habitual en un año de precios normales.

Aparte del salto cuantitativo, hay también cambios cualitativos. Aproximadamente una tercera parte de las compras se realizan como una transacción normal, $\mathbf{y}$ en las mismas poblaciones que se mencionan en el trienio anterior. El resto del cereal se adquiere mediante una fórmula que será la habitual durante la siguiente centuria: el "señalamiento". Consiste esta operación en comprar antes de la cosecha el grano necesario, pagando un anticipo o señal en función del precio que se espera alcance el producto en septiembre. Con ello, la alhóndiga se asegura un volumen de compras importante en un momento óptimo respecto al precio. Al llegar la fecha convenida, se pagaba el resto del valor, fijando el precio mediante la media aritmética de tres mercados consecutivos: el de la Virgen de Septiembre, el anterior y el siguiente. Si se comprara, en el caso concreto de 1596/97, en el que se compra mediante los dos sistemas, el precio medio obtenido en uno y en otro, se observa que resultaba muy ventajoso para el granero público. Mientras que el trigo comprado mediante señalamiento se acaba pagando a 11’25 rs./fs., el resto alcanza un valor medio de 12`81 rs.

La reserva mediante señal representaba, además, ventajas adicionales. Equivalía a un préstamo sobre la cosecha, que lógicamente afectaría al pequeño campesinado sobre el que se podía ejercer una mayor presión - los grandes propietarios podían esperar a vender en el momento de precios más altos-. El tipo de operación, en realidad una variante de la mohatra ${ }^{24}$, era utilizado por los particulares, especialmente mercaderes y artesanos con cierto nivel de riqueza, para encubrir la usura. El campesino que necesitaba con urgencia liquidez antes de la cosecha, declaraba en el contrato recibir una cantidad de dinero en concepto de anticipo mayor de la que en realidad percibía, representando la diferencia el interés ilegal del prestamista. Por otro lado, cuando llegaba el momento de liquidar la transacción, este último podía, a cambio del producto contratado, pagar en especie, es decir, en cera o en cualquier otro bien que fuera absolutamente inútil para el prestatario, el cual, para evitarlo, admitía que el precio fuera menos que el de mercado ${ }^{25}$. No es difícil imaginar las posibilidades que este sistema ofrecía a quienes controlaba la gestión del pósito, esto es, los oficiales del Ayuntamiento, para presionar a los pequeños propietarios.

Por otro lado, tales préstamos no se ofrecían sólo a los campesinos de Santo Domingo. En principio el Pósito era un servicio público con unas posibilidades de

24. Sobre este tipo de contratos, sus antecedentes y sus variantes vid. GRICE-HUTCHINSON, 1982, en especial pp. 71-76.

25. Ejemplos de estos contratos particulares en Logroño se recogen en TORREALBA, J. G., 1992, pp. 109-110. 
intervención limitadas al espacio económico constituído por el municipio. Pretender servir a un área más extensa supondría, según ese criterio un contrasentido. Sin embargo, gracias a lo excepcionalmente minucioso de las cuentas de este año, sabemos que no era así. A cualquier forastero le bastaba con presentar un fiador que fuera vecino de la ciudad para obtener un anticipo. Los prestatarios provienen más o menos de los mismos lugares donde se aprovisiona el Pósito. Pero, tratándose de una operación crediticia, representa una zona de influencia considerablemente grande, destacando por la cantidad de trigo contratado algunos lugares distantes más de 20 kilómetros $^{26}$. Si este sistema podía resultar interesante como mecanismo de presión dentro de la propia ciudad, aún lo era más en la comarca en la que ejercía como mercado principal; y no digamos en las aldeas de su jurisdicción, en un periodo en el que en todas partes se multiplican los pleitos por exención de señorío.

El siguiente periodo del que se guarda la contabilidad es 1598/99. Nuevamente nos encontramos con un respetable aumento de los recursos, llegando a disponer ese año de más de 50.000 rs —un $25 \%$ más que el año anterior-. Precisamente, en noviembre de 1598 el Consejo accedió a la petición de la ciudad para contraer un censo de 2.000 dcs. con el fin de comprar trigo, alegando que ese año no se había cogido cosecha ${ }^{27}$. Sin embargo, no hay rastro de tal préstamo en las cuentas. Si el censo se había contratado antes de recibir el permiso oficial no aparecería reflejado en ellas y quedaría así explicado ese incremento del capital. Aunque también existe la posibilidad de que el dinero se empleara para financiar las carnicerías ${ }^{28}$.

Sea como fuere, lo cierto es que se mantiene el sistema mixto aunque las compras son mucho más reducidas, lo cual no deja de resultar paradójico, en una coyuntura muy negativa. El precic medio pagado ese año supera los 17 rs./fs. (casi un $45 \%$ más que en 1596). Si descontamos lo ingresado mediante el pago de señal (alrededor de la mitad se pagó a sólo 14 rs.), el precio del resto —más próximo al de mercadoasciende a 20 rs. Para recabar recursos se acudió a la mediación del Obispo de la diócesis, quien accedió a librar 100 fs. en Murillo de Rioleza y otras 288 en San Pedro de Yanguas, fuera de la zona normal de aprovisionamiento, al precio de la tasa fijado por el Corregidor (14 rs.), haciéndose la ciudad cargo de su transporte.

Otro recurso extraordinario empleado ese año fue estimular la concurrencia de vendedores forasteros ofreciendo un sobreprecio en concepto de portes a razón de 10 mrs. por legua y por fanega. Además, las alcabalas las pagaría el pósito y no el vendedor - representaban unos 7,5 mrs. por fanega-. Por último, el Corregidor aún

26. Quintanaloranco, Valluércanes, Treviana y Altable, todos ellos dentro de la cuenca del río Tirón, suman casi un $15 \%$ del cereal contratado ese año.

27. A.M.S.D., Cuentas del Pósito, leg. 51.

28. El año siguiente es cuando se realiza la petición mencionada en el texto recogido en la nota 9: «Esta çiudad tiene en pie dos mill ducados que abia tomado a çenso para el probeimiento de las carneçerias del año pasado; V. Magd se sirba que dellos se pueda dar de comer a los pobres y aun a los veçinos, porque como ha çesado el comerzio no venden cosa de sus oficios porque no entra persona en esta ciudad ha mas de dos meses porque de otra manera va perdida de todo punto esta ciudad» (A.H.N., Consejos, leg.27.900). 
consideró insuficientes estas medidas y ordenó en noviembre un embargo -aunque en la orden se evita este término ${ }^{29}$ — pagándolo a los mismos 14 rs.

A pesar de todo, la cantidad de cereal que consigue acumular el pósito es la más baja de este periodo, si bien la suma invertida en ello es mucho más alta, una cifra fabulosa incluso comparada con las que aparecen en la segunda mitad del siglo XVII. Sin embargo, el resultado final de la gestión fue mucho más positivo de lo que se vio en la crisis de 1582. La diferencia entre el precio de compra y el venta fue menor en esta ocasión, de tal forma que los consumidores pudieron adquirir el pan a un precio realmente mucho más barato que el corriente. Por su parte, el Pósito no sólo no sufrió pérdidas, sino que incluso obtuvo un pequeño beneficio.

El año siguiente, con una cosecha no tan mala, se siguió la misma tónica, invirtiendo una suma considerable en compras, aunque esta vez a un precio menor, es decir, acumulando mucho más grano. Nuevamente, se dio una proporción de dos tercios de compras mediante señalamiento. A partir de ese momento, el acopio se hizo cada vez más desproporcionado con las necesidades; unas necesidades decrecientes dado el terrible impacto demográfico de la peste de 1599. El año siguiente sólo se "panadeó" una tercera parte de lo acumulado, quedando lo demás "en ser" (o sea, sobrando) más de 2.000 fanegas. En 1602, el patrimonio inicial en especie ascendía a 4.191 fanegas de trigo. Se declaraba, por otro lado que:

«...por orden y mandado de los s(eñore)s Jus(tici)a y rregimiento desta ciudad se dieron prestadas a v(ecin)os desta ciudad quinientas e veinte fanegas del tr(ig)o de la dha londiga por el daño que se declaro y va rreçiviendo el dho trigo por aber mucho y no se poder traspalear e que se comenzaba a gorgogear.... ${ }^{30}$.

A pesar de estos problemas, aún se compraron otras 433 fanegas, empleando esta vez sólo el sistema de anticipo, aprovechando el buen momento de los mercados. Además de vender a las panaderías casi 3.000 fanegas, aquel año se prestaron otras 1.000 , iniciando la práctica de préstamos masivos que caracteriza el modelo de gestión que encontramos más tarde. Hay que advertir que, contrariamente a lo que sucede con la compra mediante anticipo, los préstamos en especie se otorgan exclusivamente a vecinos de la ciudad o, en todo caso, de las vecinas aldeas de Corporales y Morales, dependientes de la jurisdicción de Santo Domingo.

En esta ocasión, en una coyuntura mucho más difícil que la de 1582, el balance de la gestión fue mucho más positivo. La institución salió reforzada, contando desde ese momento con unos recursos muy sólidos, probablemente incluso superiores a los de otras localidades más importantes y más ricas en proporción a su población. Por

29. La partida contable dice así: «Yten pareçio por el libro de las dhas compras quel dho señor corregidor considerando la falta quel dho año avia para poder proveer la dha alondiga hiço que las confradias cavildo de la iglesia desta ciudad y personas que tenian venta de trigo en ella diesen para la dha alondiga dusçientas y noventa y nueve fanegas y media de trigo mandando al dho mayordomo las pagase a los de las diesen a rraçon de catorçe reales...» (A.M.S.D., Cuentas del Pósito, leg. 51).

30. A.M.S.D., Cuentas del Pósito, leg. 51. 
otro lado, la oligarquía de Santo Domingo contó con un mecanismo de presión social, pero también de apaciguamiento muy poderoso y, además, autofinanciado.

\section{El Modelo de Gestión en la Segunda Mitad del Siglo XVII}

En el funcionamiento del pósito que puede observarse en la documentación correspondiente a la segunda mitad del siglo XVII se materializan las lineas marcadas en el ultimo periodo analizado. La fórmula que adopta la contabilidad es muy similar. Unicamente desaparece el registro pormenorizado de los lugares de compra. Se menciona que las compras tienen lugar en todos los casos en el propio mercado de la ciudad y, presumiblemente, el producto seguía proviniendo de una comarca muy reducida en torno a ella.

Los niveles de endeudamiento que reflejan los datos disponibles para el siglo XVII, no son superiores a los que veíamos al hablar del trienio 1579/82. Se da la circunstancia, además, de que el recurso al crédito, en la única ocasión en que se produce, se apoya sobre el desvío de algunos de los fondos de la saneada hacienda local hacia las arcas del pósito, además de en la contratación de censos. En 1642 se contrataba un censo con un particular por valor de 4.254 rs. Pero, al mismo tiempo se tomaban, del patrimonio de las carnicerías públicas otros 1.250 rs. Salvo este caso, no aparece ninguna otra referencia al pago de intereses, por lo que debemos suponer que fue la única vez en los ocho años analizados en la que se precisó de financiación exterior.

La venta de pan permanece como una de las actividades fundamentales. Las cantidades dedicadas a ese fin son bastante estables, oscilando entre las 1.200 y las 1.800 fanegas. Sólo en el año 1697 la cantidad desciende a 168 fanegas. El motivo de esta excepción fue, como veremos más adelante, un problema puntual de falta de liquidez. Por lo demás, la forma que adopta esta actividad es muy diferente a la observada en el análisis anterior. El control por parte del Ayuntamiento se hace mucho más directo y se normaliza, en el sentido de que es muy similar al que puede verse en otras poblaciones. Todas las ventas se centralizan en las panaderías, cuya retribución se fija de forma estable en dos maravedís por cada cuartal vendido. La distribución del trigo se hace en partidas lo suficientemente pequeñas como para que no se presenten los problemas que tienen otros pósitos. En algunos, la emisión de grandes cantidades de pan produce una caída del precio que pone en peligro su rentabilidad, viéndose obligadas las autoridades a retirar del mercado una parte (con los problemas de almacenamiento que ello supone, especialmente si ya se ha transformado en harina) o a cerrar el mercado interno forzando el consumo a un precio superior al de mercado, lo cual constituye una decisión sumamente impopular. Ninguna de estas circunstancias se producen en los casos analizados para Santo Domingo.

En cuanto a la evolución de los precios medios de venta del pan respecto a los de compra (ver gráfico 4), persiste la tendencia a que el granero obtenga beneficios casi todos los años, constituyendo ese beneficio su principal fuente de financiación. No 
obstante, las diferencias son, en general, menos acusadas que en otros lugares. Ello a pesar de que el grado de comercialización de la producción ceralícola en la zona y su condición de abastecedora de las localidades viticultoras próximas justificaría una mayor amplitud en la oscilación de los precios de cosecha a cosecha. Sin duda ello

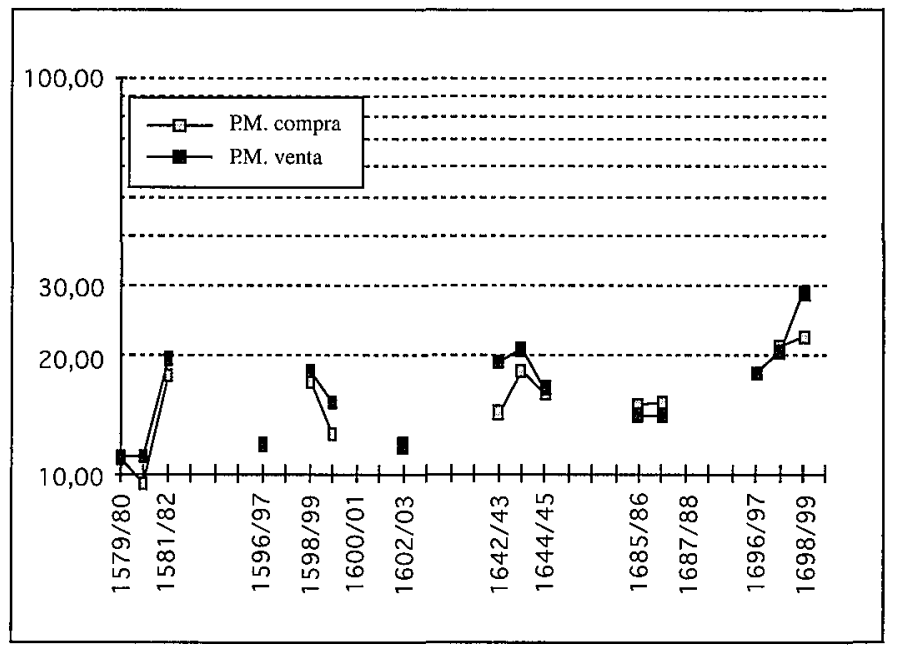

Gráfico 4: Evolución de los precios de compra y de venta.

se consigue gracias a la posibilidad de obtener precios muy convenientes mediante las compras con señal.

Las novedades que aparecían a comienzos de siglo, el préstamo de trigo para la sementera y el señalamiento, se consolidaron como rutina sistemática ${ }^{31}$. La primera no presentaba ninguna diferencia respecto a su homóloga en Calahorra. La segunda contenía una variación más de nombre que de contenido, respecto al préstamo en dinero para la cosecha practicado por el granero calagurritano. Equivalía, en realidad, a un anticipo sobre la cosecha sin interés nominal, aunque ya hemos visto cómo el precio impuesto por el Ayuntamiento, correspondiente al momento de mayor abundancia, era muy ventajoso. Los préstamos en especie tampoco tenían ningún interés nominal.

Veamos ahora las consecuencias de este funcionamiento. En primer lugar, la composición del patrimonio al inicio del ejercicio era muy diferente. No estaba constituido únicamente por una cantidad de dinero en metálico. Además de él estaba compuesto por otros dos conceptos: por un lado, una cantidad en especie prestada a los agricultores, cuya responsabilidad de cobro corría por cuenta del mayordomo entrate. Las cantidades dedicadas a sementera oscilan entre las más de 2.000 fanegas de 1642 y las 857 de 1698; sin contar con el hecho de que en 1699, debido a la gravísima carestía general en toda Castilla, no se prestó cantidad alguna. Excepcionalmente, en 1698, se repartió directamente el dinero del pósito, antes de comprar trigo. En noviembre aún no había llegado la provisión Real concediendo el permiso para el reparto de la tercera parte del trigo. Para no alterar el precio de los mercados, no se

31. Ver gráfico 5. 
había adquirido cantidad alguna ${ }^{32}$, por lo que no había suficiente cantidad en la alhóndiga. Como se consideraba bastante el dinero procedido de la venta del pan, se optó por derramar la tercera parte de él ${ }^{33}$. Pero salvo en esta ocasión, la operación equiva-

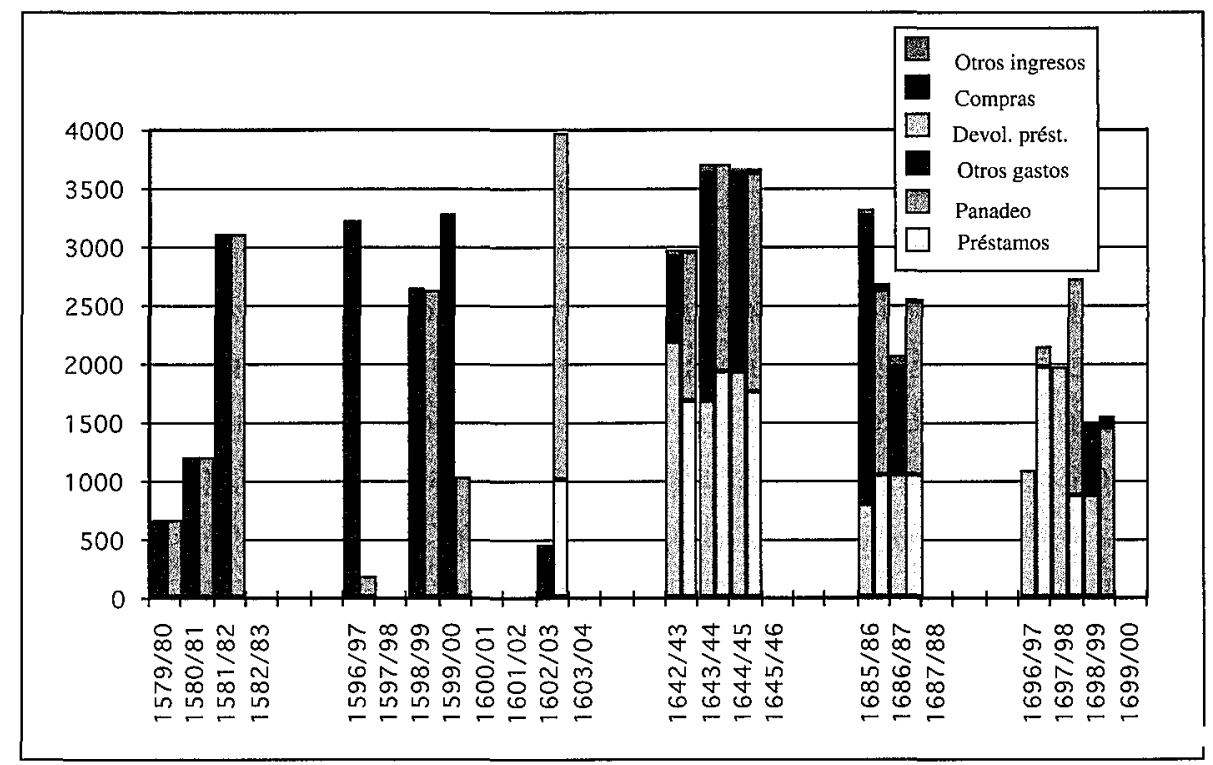

Gráfico 5: Ingresos de trigo y usos a los que se dedica.

lente al crédito monetario que puede verse en otras poblaciones, la ocupa aquí el pago de anticipos a cuenta de la cosecha, y los préstamos se conceden sólo en especie.

La cuantía máxima de tales préstamos en especie venía determinada, en teoría, por la del volumen de que disponía la institución. La facultad, concedida por el rey, que permitía llevar a cabo la operación de crédito especificaba que se podía dedicar a ella hasta un tercio de los ingresos en especie. En la práctica no se respetaba este límite y la decisión quedaba al arbitrio de los regidores sin que el delegado real opusiese ninguna traba.

Finalmente, el patrimonio recibido por el administrador incluía el compromiso adquirido por algunos labradores de vender su cosecha, a cambio del cual habían recibido una señal considerable. A efectos contables, estas cantidades figuran como deuda de dinero a favor del pósito --véase gráfico 6-. Esta partida es la que experimenta mayores oscilaciones y representa la práctica totalidad de las adquisiciones efectuadas. Al sustituir las compras normales por esta operación crediticia, el granero se aseguraba un mecanismo adicional de control indirecto del comercio de granos. Por mucho que subieran los precios y los productores se vieran tentados a llevar su

32. En la sesión municipal del 25 de abril de 1699 se alertaba sobre la subida de precios en el mercado: el trigo se vendía a 35 y 36 rs. la fanega; la cebada a 15 y a 17 rs; el centeno a 27 . Se denunciaba además que las panaderías hacían mal pan. No pudiéndose empezar el trigo del pósito hasta mayo porque sólo había 1.200 fanegas, se decidió enviar propios a Santa Coloma para pedir a sus panaderías que vinieran con pan cocido, ofreciéndoles $2 \mathrm{mrs}$. por encima de los 9,5 cuartos que costaba el cuartal en Santo Domingo (A.M.S.D., Actas, leg. 9/9).

33. A.M.S.D., Actas, leg. 9/9, sesión de 20 de noviembre de 1698. 
mercancía a otros lugares, el compromiso adquirido aseguraba que una buena parte de la producción se quedara en la ciudad, evitando recurrir para ello a prohibiciones expresas, siempre mucho más impopulares.

La suma de todos estos conceptos constituye el capital de la institución, cuya evolución se refleja en la gráfica 6. Existe el problema de tener que representar valores heterogéneos. Como mal menor he optado aquí por dar al trigo el valor potencial
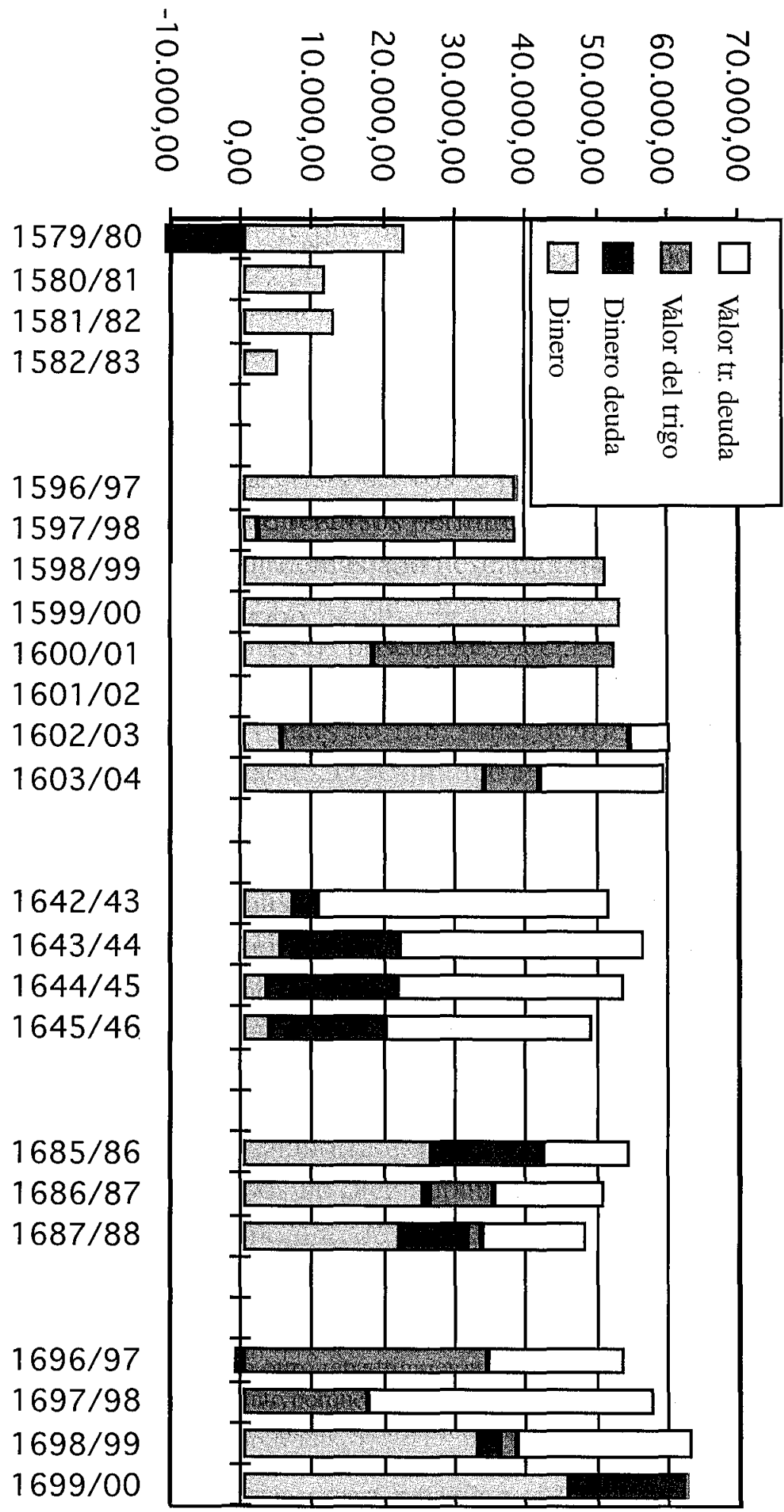
máximo, multiplicándolo por el precio medio de venta de cada año, pero sin perder de vista las cantidades reales, expresadas en el gráfico 7, en la que se representan las existencias en especie sin transformación alguna. En definitiva, lo que se pretende mostrar es cómo se mantiene un patrimonio bastante estable respecto a su cuantía y muy variable respecto a su composición.

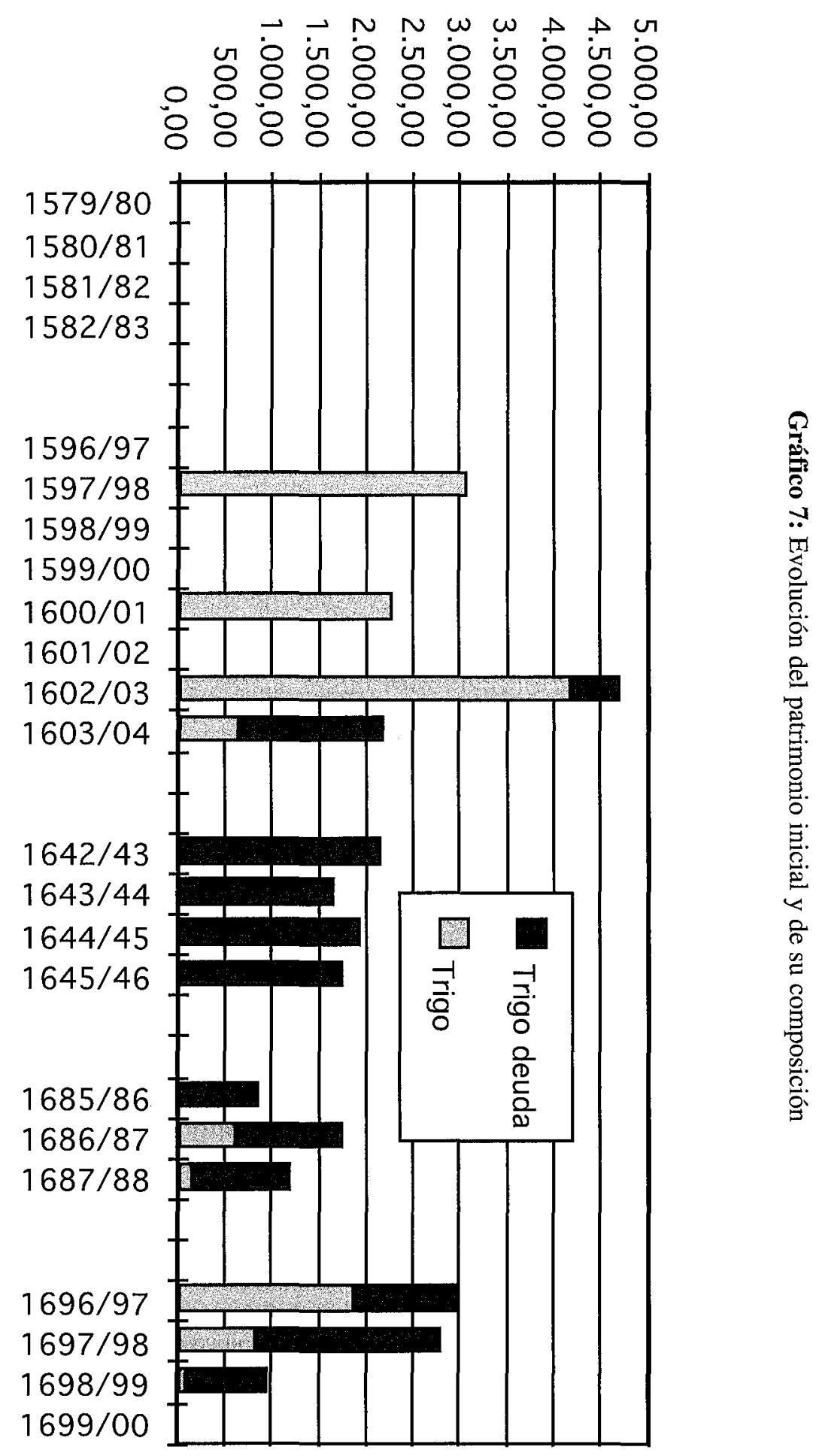


En el trienio 1643/46, en el que los precios de adquisición oscilan entre los 14 y los 18 reales, únicamente se transfieren de un administrador al siguiente el trigo prestado para la siembra y unas cantidades de dinero en metálico bastante inferiores a las que veíamos para el siglo XVI, además de tener reservadas, mediante el pago de una señal, alrededor de 1.800 fanegas de cereal. En el bienio 1685/87, con unos precios bastante más bajos, el dinero en metálico pasa a constituir la parte substancial del capital, muy por encima de las demás partidas. En los últimos tres años del siglo, los precios son los más altos de la muestra. En buena lógica, debería reducirse el dinero contante, depreciado respecto al trigo, y así sucede en el primer año. Sin embargo, esto produce unos fuertes problemas de liquidez, sucediéndose los saldos favorables al administrador, por lo que se opta por reducir los préstamos y las compras y aumentar la venta del pan. Por otro lado, a finales de siglo, lo peor de la tormenta monetaria ya había pasado gracias a las medidas adoptadas por Medinacelli en $1680^{34}$.

Gracias a la posibilidad de consultar las actas municipales para el último quinquenio del siglo XVII, se han podido complementar las fuentes cuantitativas de las cuentas procedentes de los Juicios de Residencia con otras noticas cualitativas. A pesar de la gravedad de la crisis de 1699, puede verse cómo el pánico es mucho menor y la disponibilidad de recursos permite a los regidores atender mejor sus propios intereses, sin descuidar demasiado descaradamente el del público.

Durante el trienio 1696/99, sólo se compró trigo en la última campaña en una cuantía no demasiado elevada (poco más de 600 fs.). Por otro lado, las cantidades de trigo destinadas a préstamos y a la venta de pan fueron variando a remolque de la evolución de los precios. A medida que se elevaban, mayor era la cantidad dedicada al panadeo, reduciéndose los empréstitos en especie hasta desaparecer. No hay variación en este comportamiento respecto a lo que sucedía en las crisis del siglo anterior.

Durante las dos campañas anteriores a la crisis, la actividad que reflejan las actas municipales se puede considerar normal. En enero de 1698, el Ayuntamiento parece remiso a conceder préstamos en especie, puesto que, después de un primer reparto, accede a un segundo alegando demandas populares en este sentido ${ }^{35}$ En noviembre de ese mismo año, ya bajo la administración de otro mayordomo, es cuando se procede al préstamo en metálico a devolver en especie mencionado más arriba ${ }^{36}$. En ese momento se establecía la estimación del trigo en 21 rs. la fanega. Unos meses más tarde, en abril del año siguiente, se denunciaba que el precio se había disparado hasta

34. KAMEN, 1981, pp. 170-173.

35. Se ordena que «...se haga ottro reparttim(ien)tto de ttrigo prestado de la lóndiga enttre los que faltaren despues del primer reparttimiento porque muchos pobres lo piden= para lo qual se acuerda se heche bando para que denttro de quattro dias acudan a sacarlo rrepartido...» (A.M.S.D., Actas, leg. 9/9, sesión de 10 de enero de 1698).

36. Vid. el contenido de la sesión a que se refiere la nota 23. 
más de 35 rs. ${ }^{37}$. Veamos a continuación cuáles fueron las medidas extraordinarias que se tomaron.

La primera, decretada en abril, consistió en acudir a las panaderías de una población próxima para forzar a las de Santo Domingo a mejorar el abasto. Es decir, ni siquiera se emprendió una acción directa contra ellas. Poco después la situación se deterioró muy rápidamente, y las decisiones se adoptaron en cascada: El 14 de mayo se fijó un precio máximo para el comercio no intervenido, de 22 rs. por fane ga, al tiempo que se ordenaba la venta de 100 fanegas del Pósito a 24 rs. (la diferencia constituía el márgen de los panaderos); El 22 de mayo, el Corregidor ordenaba el aforo o registro del cereal de los vecinos para proceder, cuando fuera necesario, a su embargo; Sólo una semana más tarde, se elevaba la tasa hasta los 28 rs. — también para el trigo de la alhóndiga-; El 30 de mayo se estipulaba que el pan municipal se vendiera sólo en un lugar determinado, para garantizar el control sobre los compradores; El 23 de junio, se establecía una nueva vigilancia, en esta ocasión para impedir la entrada de transeuntes que no vinieran a trabajar y que se introducían con la excusa de la siega, aumentando el consumo del pan. Esta medida equivalía a condenar al hambre, fuera de los muros de la ciudad, a toda la población marginal sin filiación fija ${ }^{38}$.

Todas estas medidas apuntan a una situación realmente crítica, a la par que indican una clara supremacía del delegado real a la hora de hacerle frente. Sin embargo, cosa impensable cien años antes con los recursos disponibles y la modalidad de gestión de la época, se produjeron resistencias muy significativas entre los munícipes. El 7 de agosto, el Procurador Síndico General recordaba la órden del Corregidor de proceder al embargo al precio de la tasa, advirtiendo que sólo quedaban 140 fanegas en el Pósito y que el precio estaba entre 46 y 50 rs. y proponiendo un nuevo embargo. Véase cuál fue la respuesta de los regidores a esta demanda:

«El Señor Corregidor propusso y dijo que ayer viernes siette del corrientte en el aiuntamiento que se zelebro con zedula antte diem se izo nottoria una pettizion de el señor Procurador General, tocante a que se entrase trigo en el posito y londiga desta ciudad para el susttentto de estta republica por yrse acavando lo que avia en el [...] y vista y enttendida por dhos señores se ttratto y confrenzio sobre el caso que es de matteria tan ymporttantte $=\mathrm{y}$ dhos cavalleros y señores regidores unanimes y conformes dijeron que lo primero que se les ofreze es suplicar al señor Corregidor como lo azen se sirva mandar se aga reintegrar el posito de ttodo el ttrigo y dinero que se le estta deviendo, pues le constta a su merzed de los que son deudores lexittimos $=y$ lo segundo, echa esta dilixencia, se acuerda que, rrespectto de que en los mercados de estta ciudad se va aumenttando la entrada de ttrigo con la nueba cosecha de este año, para quando se acave el ttrigo que oy ttiene el posito, se busquen astta doze panaderas de las que asta aqui an llevado dho trigo y echo pan cozido justificadose de su

37. Vid. texto de nota 25. Si se comparan los precios que se mencionan en dicho texto con los $28,7 \mathrm{rs}$. de media que alcanza el trigo vendido por el Ayuntamiento ese año, se ve que, a pesar de la subida respecto al año anterior, es mucho más bajo que el de mercado.

38. A.M.S.D., Actas, leg. 9/10, sesiones correspondientes. 
convenienzia, las quales con sus caudales acudan a los mercados y donde mas lo allaren, y compren ttrigo a el precio que corriere comunmentte y a este respecto se venda el quarttal de pan cozido $\mathrm{y}$, en caso de que algunas de las panaderas que se considerare tener caudal lo resisttieren, se les apremie a ello y si consttare ser pobres y no tener caudal para las compras, se les de a cada una del dinero que ttiene en ser el dho positto, prozedido del ttrigo que se les a dado para cozer, a duzientos reales por una vez, que sirva de caudal para la primera compra, y con el pan que sacaren de ella se siguen las demas y que den fianzas de bolver dho dinero quando se les pida y que se cuide de que no saquen el dho pan fuera de esta ciudad pena de perdido y se eche vando para ello= y asi mismo para que todos los demas vezinos que quisieren panaderear al prezio de dhas panaderas lo puedan azer libremente $=$ asi se acordo por dhos señores regidores y el señor Corregidor conbino en ello, pero con protesta que izo de dar quenttas a los señores de el Consejo para que provean lo que fueren servidos $=y$ en quanto a el primer punto, sobre que dhos señores regidores llevan dho y suplicado al señor Corregidor, de que se reinttegre el posito de lo que se le deve attrasado, dijo su merzed estta pronto a hadministtrar justtizia y que entregandosele memoria de los debitos, con distinzion de personas y canttidades, la enttregara a un ministtro suio para que la ejecutte... $\rangle^{39}$.

He considerado que valía la pena recoger el texto completo a pesar de su extensión. Es difícil imaginar mayor sangre fría, tanto frente a la carestía como frente al representante de la autoridad $\operatorname{Real}^{40}$.

Pocos días después, el 19 de agosto, se celebró una sesión extraordinaria, en ausencia del Corregidor, su teniente y varios regidores, que se encontraban fuera de la ciudad. En ella, D. Alonso de Ocio, otro de los regidores perpetuos, decía cómo en el mercado del sábado anterior los panaderos no habían comprado trigo, a pesar de quedar existencias en la alhóndiga sólo para dos días, por consejo del procurador síndico, quien les había asegurado que perderían dinero comprando muy caro cuando la "postura" del Ayuntamiento no sería mayor de ocho cuartos el cuartal. Con estos argumentos, D. Alonso tomó, como regidor más antiguo de los que quedaban, la vara de Justicia y convocó a los panaderos en la plaza para tratar sobre ello, pidiéndoles

39. A.M.S.D., Actas, leg. 10/10, sesión de 8 de agosto de 1699.

40. El mes anterior ya se habían dado muestras de tal resistencia: «Por el señor Dn Alonso de Ozio se propuso y dixo que la Sancta Yglesia desta ziudad avia otorgado poder para suplicar a Su Magestad y Señores de $\mathrm{Su}$ Real Consejo se sirbiese de mandar que el señor Corregidor desta ziudad abriese las puertas de ella, que tenia zerradas con el motivo de que no se vendiese ni sacase para fuera el trigo que tenían diferentes vezinos desta ciudad, y que dejase al estado eclesiastico y secular vender lo que tubiere publicamente como se pudiesen conzertar, abriendo el comerzio, respecto de haverse considerado que en el posito y londiga desta ziudad avia el trigo nezesario para el sustento de los vezinos y biandantes hasta lo de la proxima cosecha de este año, cuio poder otorgo dha Sancta Yglesia por no averse servido el señor Corregidor permitir dha venta de trigo ni abrir dhas puertas, sin embargo de un requirimiento que se le havia hecho por los comisarios de dha Sancta Yglesia y los desta ziudad que han yntervenido en la disposizion del trigo y otros granos que avian rexistrado en virtud de ordenes $R($ eale)s, de que se ha tratado largamente en ottros aiuntamientos= Y que para que llevase efecto el yntento de vender su tr(ig)o libremente y que pudiesen vivir los de uno y otro estado, suplico a la ziudad biese si gustava ottorgar su poder quo adiubando y adiriendose a el de dha Sancta Yglesia= Y, entendida esta proposizion por dhos señores, se confirio y ttrato largo sobre ella y ubo diferentes dictamenes, y el señor Corregidor dixo no se avia de ottorgar el dho poder y del mismo sentir fue el dho pr(ocurad)or general, y los mas de dhos cavalleros regidores dixeron que se ottorgase...» (A.M.S.D., Actas, leg. 9/10, sesión de 3 de julio de 1699). 
que hicieran sus compras en el mercado del siguiente sábado y asegurándoles que se les darían un precio competente para no perder dinero. Efectivamente, dos días más tarde el precio era de 10 cuartos el cuartal (equivalente a 40 rs. la fanega), aunque al día siguiente ya se fijaba una nueva tasa a 9 cuartos $^{41}$.

En enero del año siguiente, se declaraba que desde varios meses antes no acudían vendedores al mercado. Pero la primera preocupación en ese momento ya no era el abastecimiento, sino «...haver zesado el adeudo de alcabalas y zientos que se causava de la benta de granos en los dhos mercados, cuyo producto es el más principal para satisfacer a Su Magestad los cavezones... $\gg^{42}$. Se imputaba esta falta de actividad a no permitir que los forasteros cargasen algunos maravedís de portes sobre el precio de la tasa fijada por el rey. De todas formas el problema no debía ser tan grave, cuando la única medida adoptada fue comisionar a dos regidores para estudiar el asunto y elaborar una propuesta.

Muy poco después, en mayo ${ }^{43}$, se presentaba el problema contrario. Un regidor informaba del poco gasto que se hacía del pan del Pósito, achacándolo al hecho de permitirles vender pan de particulares. Se les ordenó, para evitarlo, que se limitaran al que se les había distribuído. Aun así, en julio aún quedaban 700 fanegas del granero público que no tenían despacho y podían estropearse ${ }^{44}$. Para evitarlo, se repartió a los panaderos a 28 rs., a pesar de haber costado más. En septiembre el Corregidor obligó a moderar el precio del pan del Pósito, mucho más elevado que el de mercado (32 mrs. el cuartal frente a 24), ante la protesta de los regidores que alegaban las mismas razones que en julio y solicitaban obligar a las panaderías a vender sólo el pan de la alhóndiga ${ }^{45}$. La imagen que se desprende de todas estas actitudes es la de un gobierno municipal mucho más confiado en las posibilidades de superar una grave crisis con el menor menoscabo posible de sus intereses.

Queda únicamente por hablar del último bloque contable, el descargo de dinero. Para los cuatro trienios está constituido casi exclusivamente por los pequeños gastos de mantenimiento y por los salarios, puesto que, como hemos apuntado, no hay apenas operaciones de crédito que impliquen pago de intereses u otros conceptos. Sólo en 1582 se registra un fuerte aumento de los gastos como consecuencia de las compras masivas que se realizan en el exterior y que implican el coste de portes, impuestos de tránsito, dietas, alquileres de graneros, etc. El ayuntamiento se vio precisado aquel año incluso a habilitar una construcción para la venta del pan. Con todo, el personal que cobra su salario del granero público en ese periodo se limita a una sola persona, el mayordomo, o como mucho, a algún artesano a quien se encarga alguna reparación. Ni siquiera consta pago alguno a un medidor.

41. A.M.S.D., Actas, leg. 9/10, sesión de 19 de agosto de 1699.

42. A.M.S.D., Actas, leg. 9/11, sesión de 13 de enero de 1700.

43. A.M.S.D., Actas, leg. 9/11, sesión de 29 de mayo de 1700.

44. A.M.S.D., Actas, leg. 9/11, sesión de 30 de julio de 1700.

45. A.M.S.D., Actas, leg. 9/11, sesión de 17 de septiembre de 1700. 
En los casos vistos para del siglo XVII, la gestión implica más personal. Además del mayordomo aparecen los siguientes salarios fijos: el regidor llavero o clavero, responsable directo de controlar y ayudar al mayordomo y que cobra bastante más que él; el medidor, que recibe una parte de su salario en especie; el portero del ayuntamiento percibe también una gratificación por avisar para la elaboración de las cuentas; por último, un escribano y un amanuense cierran la nómina. En total, los gastos anuales por estos conceptos oscilan entre los 1.500 y los 2.000 reales, una cantidad normal en comparación con otros pósitos.

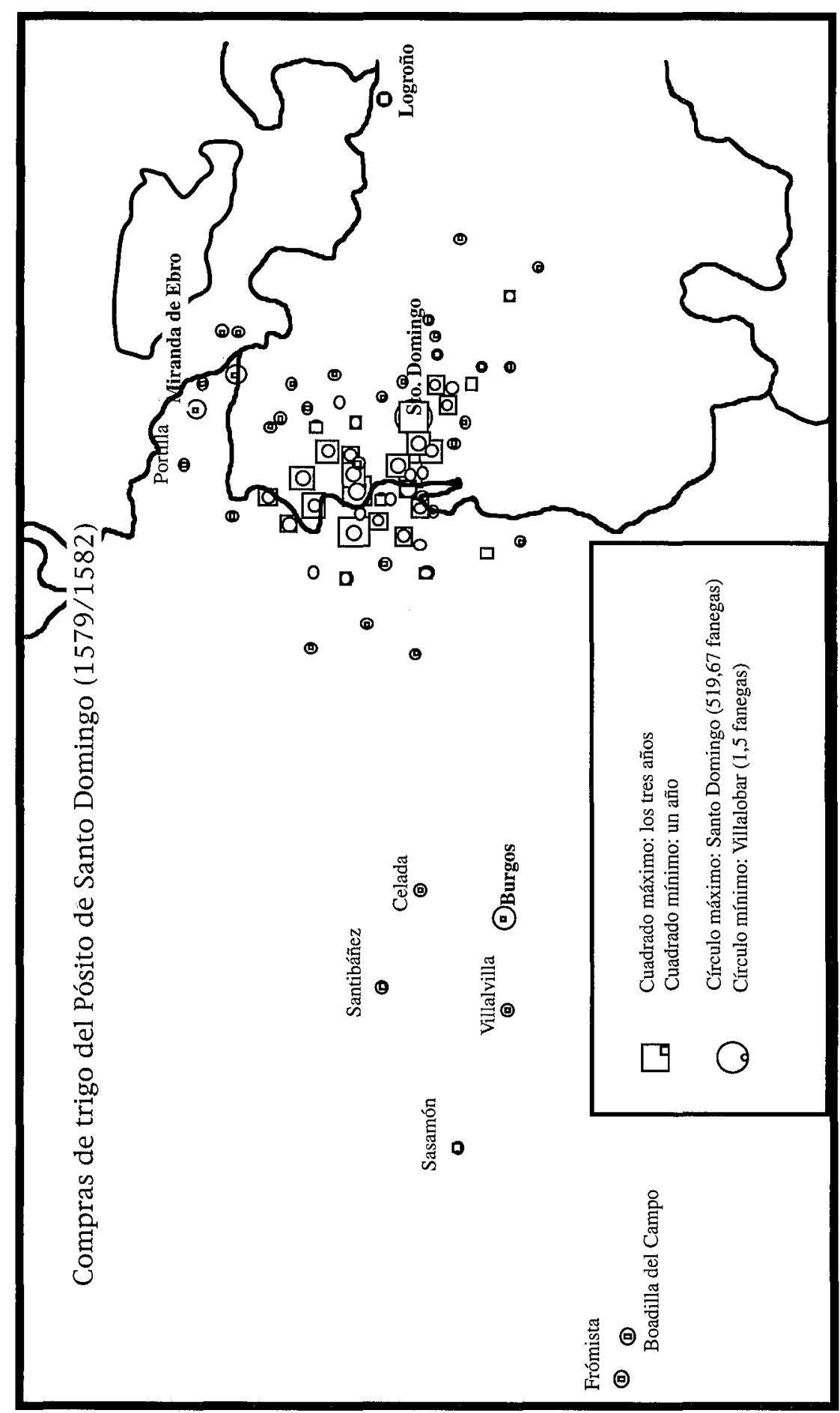




\section{BIBLIOGRAFIA}

ALONSO CASTROVIEJO, J.J. 1991

Problemática agraria y solución burguesa. Logroño, 1750-1833. Logroño.

ANES, Gonzalo. 1972

Economía e Ilustración en la España del siglo XVIII, Barcelona.

ARMAS LERENA, N. 1989

La administración del concejo logroñés en los siglos XVI-XVII, Logroño, memoria de licenciatura inédita.

\section{ARMAS LERENA, N..1994}

"El final de los jesuitas en Logroño: Poder económico e imbricaciones sociales": Artículo inédito depositado en el I.E.R., Logroño.

BRUMONT, F. 1986

"La Rioja en el siglo XVI": Segundo Coloquio sobre historia de La Rioja, Logroño, vol. II.

BURGOS ESTEBAN, FCO. M. 1989

"Las bases sociales del poder de la élite del estamento hidalgo. El linaje de los Barrón (Logroño, ss. XVI-XVII)": Brocar. Cuadernos de Investigación Histórica, 15, 91-1 17.

GÓMEZ URDÁÑEZ, J. L. Y OTROS. 1987

Cenicero histórico. Economía y sociedad en una ciudad riojana. Logroño.

GÓMEZ URDÁÑEZ, J.L. Y LORENZO CADARSO, P.L. 1993

"Las comunidades rurales frente al Estado Absoluto": Mélanges de la Casa de Velázquez, XXIX (2), 79-92.

GÓMEZ URDÁÑEZ, J.L. (DIRECTOR DEL AREA DE Hª MODERNA). 1994.

Historia de la ciudad de Logroño, Vol. III. Logroño.

GÓMEZ URDÁÑEZ, J.L. Y ARMAS LERENA, N. (EN PRENSA)

Los señorios en La Rioja en el siglo XVIII

GRICE-HUTCHINSON, M. 1982

El pensamiento económico en España (1177-1740), Barcelona.

IBÁÑEZ RODRÍGUEZ, S.1991

La producción en La Rioja: las fórmulas eclesiásticas de participación en el producto agrícola (siglos XVI-XVIII), Logroño, memoria de licenciatura inédita.

IBÁÑEZ RODRÍGUEZ, S. 1995

"El diezmo en La Rioja (siglos XVI-XVIII": Brocar, 18, 189-222 
KAMEN, H. 1981

La España de Carlos II, Barcelona.

LORENZO CADARSO, P. L. 1994

"Oligarquización y luchas políticas en el Ayuntamiento: 1512-1612": Historia de la ciudad de Logroño. Logroño, 1994, Tomo III, Gómez Urdáñez, J.L. (director area de $\mathrm{H}^{\mathrm{a}}$ Moderna).

PASTOR OCÓN, J.L. 1989

Transformaciones económicas en Murillo de Rio Leza (La Rioja) 1750-1833, Logroño.

SANTAYANA BUSTILLO, LORENZO. 1979

Gobierno político de los pueblos de España, Madrid.

TORREALBA, J. G.1992

"Comercio no institucionalizado en Logroño, 1650-1750": Berceo, 123. 